\title{
A Case Study of the Severe Convective in Bohai Sea and the Establishment of Early Warning Index on the Sightseeing Boat
}

\author{
Yanjun Zhou, Chengyu Yan, Yanjiang Li \\ The ocean observatory of Qinhuangdao, Qinhuangdao 066000, China
}

Received 7 July 2016

Accepted 10 August 2016

\begin{abstract}
Using the synchronous data such as weather radar, oceanic WRF model etc., a severe convective weather process has been analyzed on August 31, 2015 in Bohai Sea area, China. The results show that the shear line moved eastward and enhanced at the $925 \mathrm{hPa}$ and $850 \mathrm{hPa}$ in Bohai Bay from 08:00 to 20:00, the index $\mathrm{K}$ was $35^{\circ} \mathrm{C}$, index SI was $-1.81{ }^{\circ} \mathrm{C}$, the CAPE was $166 \mathrm{~J} / \mathrm{kg}$ and the vertical wind shear was $16 \mathrm{~m}^{-1} \mathrm{~s}^{-1}$ in the stratification curve at 08:00 A.M, because of this background, the severe convective weather occurred in Tianjin. The shear line moved northward at the $925 \mathrm{hPa}$ of the lower lay from 20:00 P.M on August 31 to 08:00 A.M on September 1, the convective instability energy increased, several severe convective storm cell of meso- $\gamma$ scale and meso- $\beta$ scale near the shear line have been induced in the central area of Bohai Sea, the new round of the was caused by a series of effecting of radar echo. Severe weather process CAPE was released by the strong vertical movement and water vapor convergence of the boundary layer, the cut-in of weaker dry and cold of $\Delta \theta$ se $(850-500 \mathrm{hPa})$ corresponded with the happening and impact area of the convection system in north of Liaodong bay. And this paper established the early warning model about the severe convective weather for the sightseeing boat in Bohai Sea.
\end{abstract}

Keywords: Bohai Sea, Severe convection, Ship early warning

\section{渤海强对流天气个例与游船预警指标初建}

\author{
周艳军, 燕成玉, 李延江 \\ 秦皇岛海洋气象台, 秦皇岛 066000 , 中国
}

摘要: 利用多部天气雷达、海洋 WRF 模式等同步资料, 对 2015 年 8 月 31 日渤海一 次强对流天气漏报过程进行综合分析, 结果表明: 08 时-20 时渤海湾一线 925-850 百帕切 变线东移增强, 08 时临近探空 $\mathrm{K}$ 指数 $35^{\circ} \mathrm{C} 、 \mathrm{SI}$ 指数 $-1.81^{\circ} \mathrm{C}$ 及 $\mathrm{CAPE}$ 为 $166 \mathrm{~J} / \mathrm{kg}$, 垂直风 切变 $16 \mathrm{~m} \cdot \mathrm{s}^{-1}$, 导致天津一线的强对流天气发生。20-02 时其前部低层 925 百帕 “切变线 “北 抬, 对流性不稳定能量增强, 在渤海中部的切变线附近诱发多个中 $\gamma 、 \beta$ 尺度强对流风暴 单体，在雷达回波“列车效应“下，造成了秦皇岛近海新一轮强对流天气过程。强垂直运动 和边界层水汽辐合触发 CAPE 的释放。在辽东湾北部 $\Delta \theta \operatorname{se}(850-500 \mathrm{hPa})$ 较弱干冷切入与 对流系统的发生、落区有一定对应关系。初步建立渤海旅游船舶强对流天气预警模型。

关键词: 渤海, 强对流，船舶预警

在大气西风带环流背景下, 大多数渤海强 对流天气系统是由陆地西部或北部生成后移
向海区的, 入海后稳定少变, 在东部或南部海 岸带重新发展。由渤海区域生成的强对流系统 
并由东南方向移向西北方向的个例较少, 是目 前海上船舶强对流预警技术难点问题之一。近 年来, 环渤海地区广大科技工作者克服海洋气 象灾害实况资料贾乏的不利条件, 进行了一系 列科研探索, 卢焕珍等人借助塘沽天气雷达和 自动站对产生海岸带雷暴大风的对流风暴进 行个例分析, 总结出雷暴大风雷达回波的主要 形态、大风来临前径向速度场辐合特征等; 王 彦 $^{[1]}$ 贺鞔 ${ }^{[2]}$ 、郭庆利 ${ }^{[3]}$ 孙素琴 ${ }^{[4]}$ 应用卫星资料、 多普勒雷达、闪电等监测资料对近年来海岸带 -近海发生强对流天气个例进行分析, 得出强 对流系统中地闪、云顶亮温与雷达回波关系及 “列车效应” 引发短时暴雨成因等; 郭树军 ${ }^{[5]}$ 王伟 ${ }^{[6]}$ 从利用气象灾害风险评估方法和不完 全信息下的冰雨风险评价研究, 给出陆地灾 害预警指标。上述分析均以单部雷达监测分 析为主, 对回波源、发生、发展及演变规律的 描述存在着一定的局限性, 对该海区船舶预警 研究甚少。

2015 年 8 月 31 日 20 时- 9 月 1 日 04 时, 渤海西海岸带天津至-秦皇岛渤地区出现了由 强对流天气引发的短时暴雨、大风及持续性雷 电天气，其中，大风区域出现在山海关海区， 风速最大为 $21.8 \mathrm{~m} \cdot \mathrm{s}^{-1}$; 短时暴雨分别出现在 天津和秦皇岛, 小时雨量最大达 $40 \mathrm{~mm}$; 雷电 过程持续时间达 $6 \mathrm{~h}$ 以上。较强的强对流天气 系统对区域经济造成较大影响, 直接威胁旅游 船舶航行安全, 尤其是 2015 年 6 月 1 日长江 监利水域 “东方之星 “强对流天气引发重大沉 船事故之后, 2016 四川广元又发生强对流天 气引发游船翻沉重大事故, 游船安全航行成为 社会焦点之一。因此, 加快研究海上游船强对 流预警试验研究十分迫切。入选强对流天气个
例, 匹配河北海事局海难事故资料、新建海岛 站、浮标、探空及 EC 细网格、海洋 WRF 模 式产品等同步资料, 分析入海前后的强对流中 尺度系统空间结构特征、边界层辐合线演变及 落区对应关系; 建立强对流天气概念模型, 归 纳 6-8 月近海 1-3 小时预警指标。为渤海旅游 船舶强对流天气预警技术研究提供一些新的 思路。

\section{1. 天气背景与实况}

渤海位于中高纬度之间, 受高层大气西风 带影响较大, 大多数不同尺度的强对流天气系 统是由陆地移向海区的, 并在不同的海岸带区 域获取新的能量, 重新加强发展, 影响新的海 岸带直至内陆区域, 它的生、消及演变规律仅 是天气尺度背景下的一个中尺度天气过程。

\section{1 天气背景}

2015 年 8 月 31 日 08 时 (CST) $500 \mathrm{hPa}$ 高空图上环渤海上空为弱冷空气配合的减弱 低槽, 对应 08 时（CST）低层 $925 \mathrm{hPa}$ 高空图 (图 1.a), 渤海中南部为暖空气配合的 “人字 型” 切变线, 其中渤海湾至莱州湾一线温度场 有明显暖湿平流, 这种 “上冷下暖” 垂直结构 有利于对流天气的发生发展, 在低层切变线动 力、水汽耦合下, 给未来强对流天气强度加强 提供了必要条件。20 时低层 $925 \mathrm{hPa}$ 高空图上

(图 1.b), 渤海中南部 “人字型” 切变线原地 旋转, 前部暖式切变线北抬至渤海中部, 导致 新一轮强对流天气生成发展, 中尺度系统沿东 南向西北部海岸带延伸发展。从天气背景分析 明显看出：整个过程分为两个时段, 即 31 日 08 时-20 时 “人字型” 切变线造成天津海岸带 强对流天气，31 日 20 时-9 月 1 日 02 时 “人 字型”切变线前部暖式切变为秦皇岛海岸带强 对流天气主要影响系统。
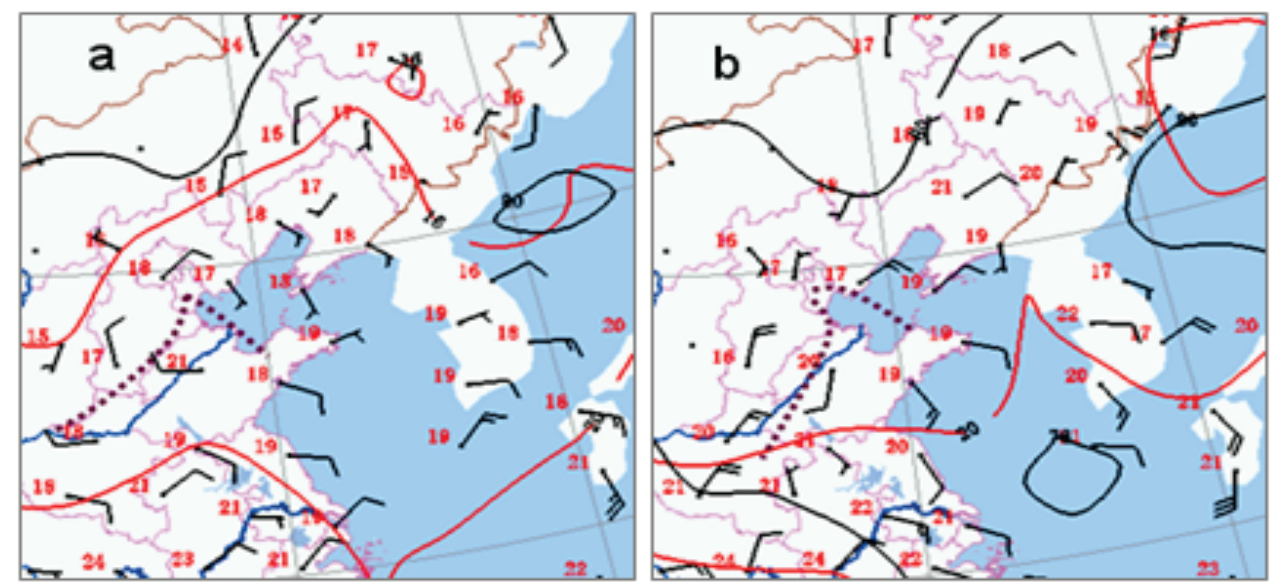

图 1. (a) 2015 年 8 月 31 日 08 时 (CST); (b) 2015 年 8 月 31 日 20 时 (CST) 为 $925 \mathrm{hPa}$ 风场（单 位 $\mathrm{m} \cdot \mathrm{s}^{-1}$ ) 温度场 (单位 ${ }^{\circ} \mathrm{C}$ ) 


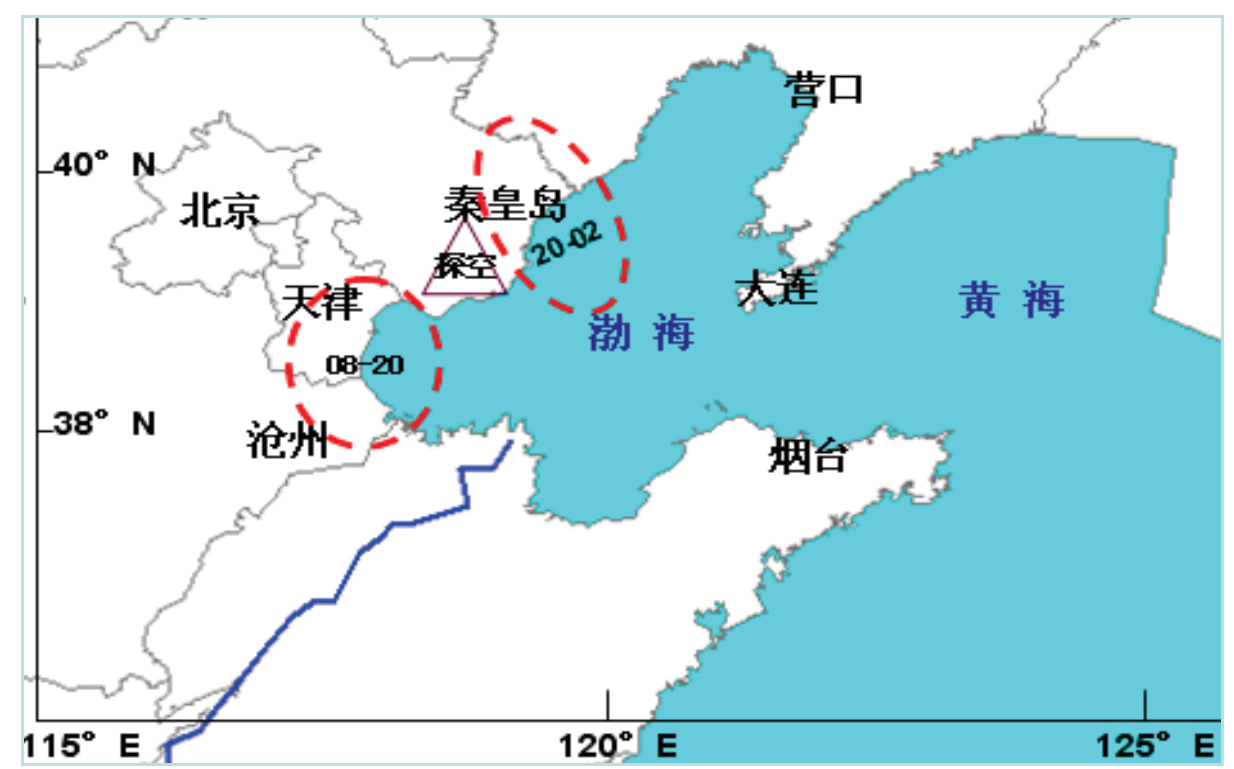

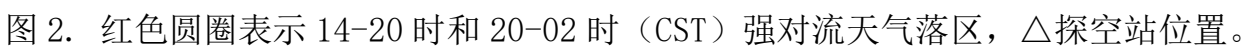

\section{2 强对流实况与探空}

对应实况与探空可分为两个不同时空尺 度见（图 2)。第一阶段为 2015 年 8 月 31 日 08 时 -20 时, 天津至渤海湾出现了由强对流天 气引发的短时暴雨、持续性雷电天气, 小时雨 量最大达 $39 \mathrm{~mm} ; 08$ 时临近探空（乐亭站）K 指数为 $35^{\circ} \mathrm{C} 、 \mathrm{SI}$ 指数为 $-1.81^{\circ} \mathrm{C}$ 及 $\mathrm{CAPE}$ 为 $166 \mathrm{~J} / \mathrm{kg}, 0-6 \mathrm{~km}$ 垂直风切变 $16 \mathrm{~m} \cdot \mathrm{s}^{-1}$, 达到一 般强对流系统发生、发展阈值或临界值。第二 阶段为 2015 年 8 月 31 日 20 时-9 月 1 日 02 时, 秦皇岛-山海关出现海区强对流引发的短 时暴雨、大风及持续性雷电天气, 大风区域出 现山海关海区, 风速最大为 $21.8 \mathrm{~m} \cdot \mathrm{s}^{-1}$; 雷电 过程持续时间达 $6 \mathrm{~h}$ 以上。20-02 时其前部低层 925-850 百帕切变线北抬, 20 时 $\mathrm{K}$ 指数 $32^{\circ} \mathrm{C}$, SI 指数为 $1.36^{\circ} \mathrm{C}$, CAPE 为 $383 \mathrm{~J} / \mathrm{kg}$, 垂直风 切变为 $19 \mathrm{~m} \cdot \mathrm{s}^{-1}$, 对流性不稳定能量进一步增 强, 海区冷暖空气交汇于渤海中部的切变线附 近, 有利于秦皇岛海岸带新一轮强对流天气发 生。

\section{2. 天气雷达监测-渤海中尺度雷达拼图}

目前, 在渤海海岸带新一代天气雷达有六 部, 如上 (图 2) 秦皇岛、天津、沧州、烟台、 大连及营口等。单部雷达 $0.5^{\circ}$ 仰角, 理论上基 本反射率监测半径 $230 \mathrm{~km}$, 径向速度 $115 \mathrm{~km}$, 由于天线高度不一致和地物遮挡, 监测距离底 高在渤海中部区域大于 $1.1 \mathrm{~km}$, 实际综合监测 能力为 $150 \mathrm{~km}$ 左右。对强对流天气发生、发 展及演变规律研究有局限性, 综合拼图与资料 共享的实现（互联网拼图 10 分钟一幅）提升 了中尺度系统的监测能力和技术水准。

\section{1 天津一线强对流天气系统入海前后的 演变特征}

对照上述同步实况及天气分析, 第一轮强 对流发生时间段为 8 月 31 日 16-18 时 (CST), 见（图 3.a1、a2）在渤海湾一带生成的多单体 风暴稳定少动, 雷达反射率因子强回波带水平 尺度 $230 \times 80 \mathrm{~km}$, 强度 $40-50 \mathrm{dbz}$, 移向 $\mathrm{W} \rightarrow \mathrm{E}$ 向, 移速为 $20 \rightarrow 30 \mathrm{~km} / \mathrm{h}$, 对应天气短时强降
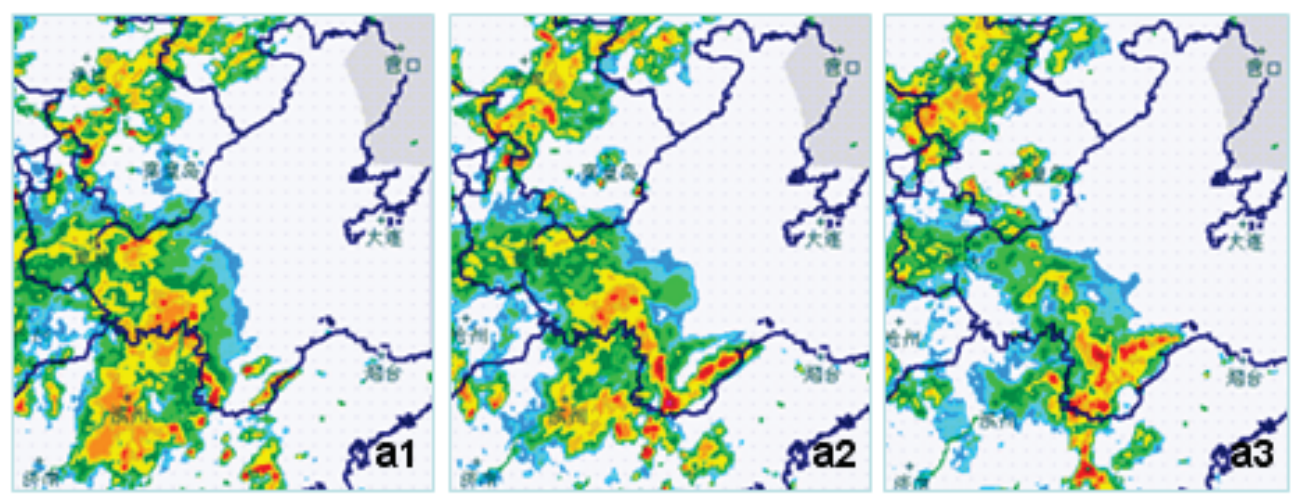

$\mathrm{dBz}$

图 3. 2015 年 8 月 31 日 16 时-18 时（CST）六部天气雷达基本反射率拼图 
水、雷电等; 2 小时后东移至莱州湾维持发展, 强回波面积缩小, 水平尺度 $180 \times 70 \mathrm{~km}$, 强度 维持 $40-50 \mathrm{dbz}$, 移向 WSW $\rightarrow$ ENE 向, 移速为 $20 \rightarrow 30 \mathrm{~km} / \mathrm{h}$ ，对应天气短时强降水、雷电、大 风等; 天津至渤海湾为一般阵雨天气。但从莱 州湾至渤海湾北部 (图 3.a3) 所谓 “暖式切变 线” 回波带已经初步形成, 并缓慢向中部海区 推进。

\section{2 秦皇岛一线强对流天气雷达回波 “列 车效应”}

初步生成的渤海南部中尺度强对流回波 带在 31 日 20 时- 22 时继续北抬发展, 见（图 4.b1) 雷达反射率强回波带水平尺度 $350 \times$ $80 \mathrm{~km}$, 强度 40-55dbz, 移向 SSW $\rightarrow \mathrm{NNE}$ 向, 移速为 $30 \rightarrow 40 \mathrm{~km} / \mathrm{h}$, 影响范围: 莱州湾-唐山 海岸带, 对应天气短时强降水、大风、雷电等; 在渤海中部的切变线附近诱发多个中 $\gamma 、 \beta$ 尺 度强对流风暴单体 (图 4 b2、b3), 与主体回 波带移向成 $90^{\circ}$ 交角, 水平尺度 $30 \times 50 \mathrm{~km}$, 强度 50-55dbz, 移向 $\mathrm{SE} \rightarrow \mathrm{NW}$ 向, 移速为 50 $\rightarrow 60 \mathrm{~km} / \mathrm{h}$, 具有明显的向前线性传播特征, 即 雷达回波“列车效应“。2 3 时-02 时渤海低层水 汽被暖式切变线西南气流源源不断地输送到 辐合线上空, 有利于中小尺度对流单体及其 次级垂直环流的维持、发展, 且这些次级环 流规则排列, 从而“列车效应”得以维持, 造 成了秦皇岛近海新一轮强对流天气过程。

\section{3 秦皇岛海区回波带消亡阶段演变特征}

从 (图 5.c1) 中明显看出 03 时 (CST) 中部海区回波带出现断裂, 强度下降至 $30-40 \mathrm{dBz}, 04$ 时趋于趋于消亡, 为一般阵雨 天气。值得关注的是在渤海湾南部沧州海区有 新的强对流回波带生成, 见（图 5.c2、c3） 水平尺度 $100 \times 40 \mathrm{~km}$, 强度 $45-50 \mathrm{dbz}$, 移向 $\mathrm{N} \rightarrow \mathrm{S}$ 向, 移速为 $35 \rightarrow 40 \mathrm{~km} / \mathrm{h}$; 整体中尺度回 波具有螺旋状特点, 相对秦皇岛海区处于消亡 阶段, 进入渤海湾的后部下沉气流垂直于沧州 海海岸带, 摩擦辐合是对流天气发生的主要动 力因素, 由于尺度偏小, 所以持续时间不足 2 小时。

\section{3. 中尺度海洋气象 WRF 模式物理量分}

析

雷达监测分析结论为暖式切变线回波带 北抬, 导致秦皇岛海区第二次强对流天气发 生。实际预报是一次漏报过程, 见下图（图 6 左）强对流落区（棕黄色）没有报出渤海中部 至秦皇岛海岸带 (红色圆圈区域), 强天气中 尺度环境场分析过程中 (图 6 右), 主要影响 系统移动方向为东移山东半岛一线 (切变线为 蓝色点划线), 绥中-秦皇岛-唐山一带没有给出 有利于强对流天气动力和水汽条件, 同时说明 此次过程可预报性偏低, 预报难度较大, 常规 的 $\mathrm{EC}$ 和 T639 数值模式对海区中尺度强对流 预报能力有一定局限性。面对服务需求, 如何
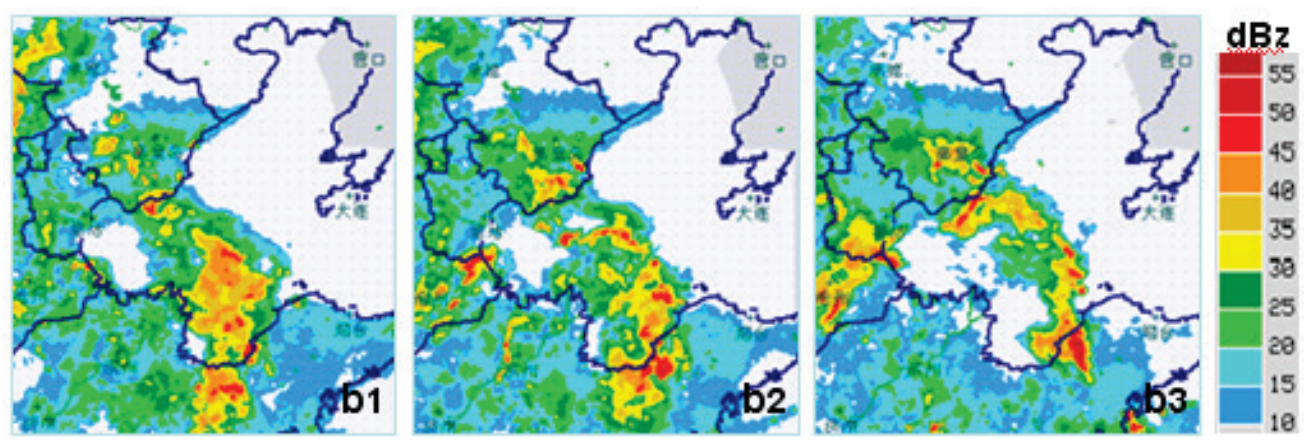

图 4.2015 年 8 月 31 日 20 时-22 时（CST）六部天气雷达基本反射率拼图
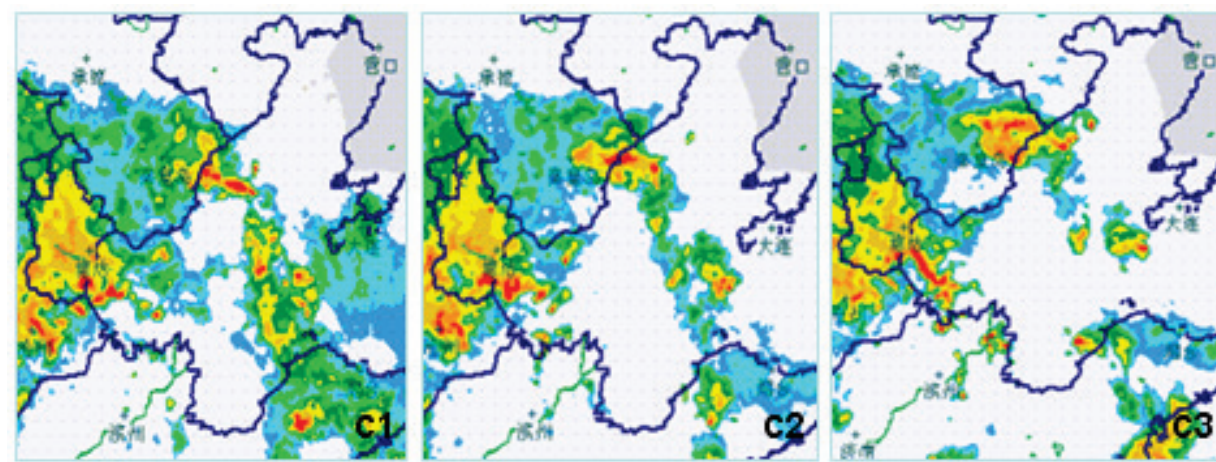

$\mathrm{dBz}$

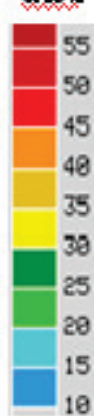

图 5. 2015 年 9 月 1 日 03 时-05 时（CST）六部天气雷达基本反射率拼图 

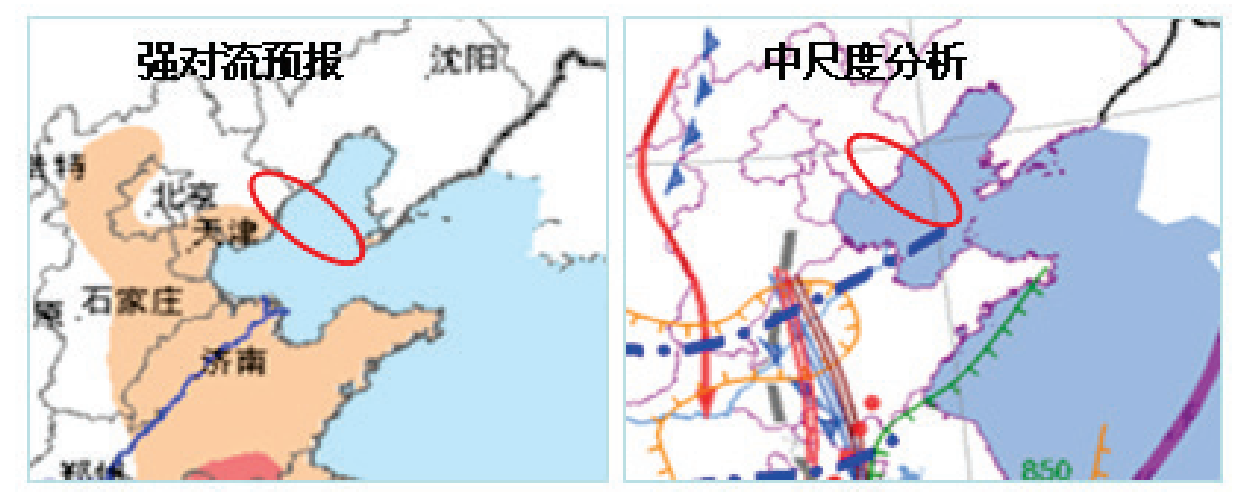

图 6. 2015 年 8 月 31 日 20 时 (CST) 中央气象台强对流预报与中尺度环境场分析, 红圈为漏报区域

降低海区强对流漏报? 可否借鉴其他模式产 品来提升实际可预报性? 通过 WRF 海洋气象 中尺度模式物理量场进行同步分析得到一些 有意义的结果。

\section{1 海洋气象 $\mathrm{WRF}$ 模式}

预报系统由中国科学院南海研究所提供 技术支持。采用 ARW (the Advanced Research WRF) 3.3 版本。按照 $1: 3$ 的比例, 外区域采用 $45 \mathrm{~km}$ 的网格尺度, 预报系统中区域采用 $15 \mathrm{~km}$ 的网格尺度, 小区域采用 $5 \mathrm{~km}$ 的网格尺度。采 用二重嵌套, 中区域为华北东部至黄渤海区 域, 小区域为渤海。主要的参数化过程包含云 微物理过程、积云参数化、长波辐射、短波辐 射、边界层参数化、陆面过程参数化以及次网 格扩散等。

\section{2 对流有效位能(CAPE)3 个时次对比分 析}

提高对流天气临近预报准确率的关键问 题是了解大气的垂直稳定度、垂直风切变及水 汽条件。对流有效位能 (CAPE) 是评价大气对流 潜力标准的不稳定指数。海洋气象 WRF 中尺度 数值模式产品提供了高时空分辨率的大气稳 定度等物理量信息, 考虑了大气层结分布, 能 够反映大气的不稳定度, 被广泛用于诊断强对 流天气发生的可能性。

从 (图 7) 对流有效位能 (CAPE) 08 时初始 场运行结果明显看出不如 14 时初始场运行结 果, 输出的 (图 8) CAPE 大值区域比较接近于 雷达实况拼图; CAPE 的 20 时初始场运行结果 (图 9) 的大值区域演变趋势更接近雷达实况 拼图, 但 “列车效应” 中、小尺度系统没有模 拟出来, 强度变化略显偏弱, 从理论上讲 20 点初始场同化资料后, 应更接近强对流发生的 物理量场和环流场, 可能与渤海实况探空资料 同化内插值有关, 对于渤海西路、北路入海强 对流系统各家数值预报之间的预报误差较小， 对于南来中尺度强对流误差偏大, 海区中、小 尺度系统移向与高层大气引导气流相反, 且持
续时间短, 就此次过程, 多家数值预报预报系 统移向为东至东南方向, 而 WRF 能预报出北抬 的趋势实属不易; 综合分析表明: 强对流发生 前对流有效位能 (CAPE) 明显增大, 逐小时强对 流回波带演变（图 4) 和 $925 \mathrm{hPa}$ 切变线（图 1.b) 与 CAPE 高值区较一致; 对比中央气象台 20 时指导预报订正预报时效可后延 6-8 小时, 预期带来的海区服务效果为正值。14 时初始 场出图时间在 20 时, 为最新的强对流天气订 正 08 时预报结论依据之一。

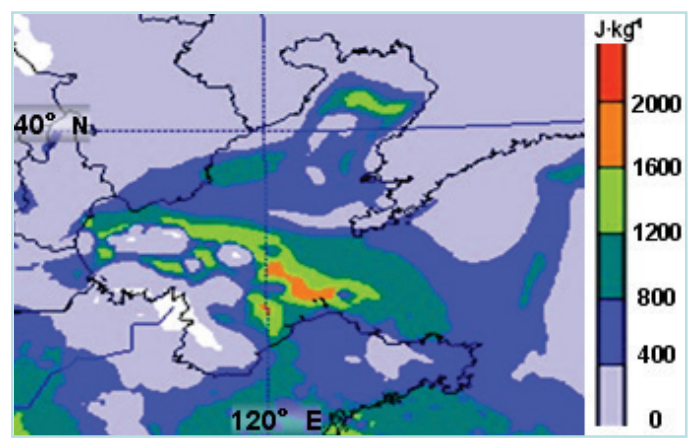

图 7.2015 年 8 月 31 日 08 时 (CST) 初始场 WRF 模式模拟渤海区域 9 月 1 日 01 时对流有 效位能(CAPE)

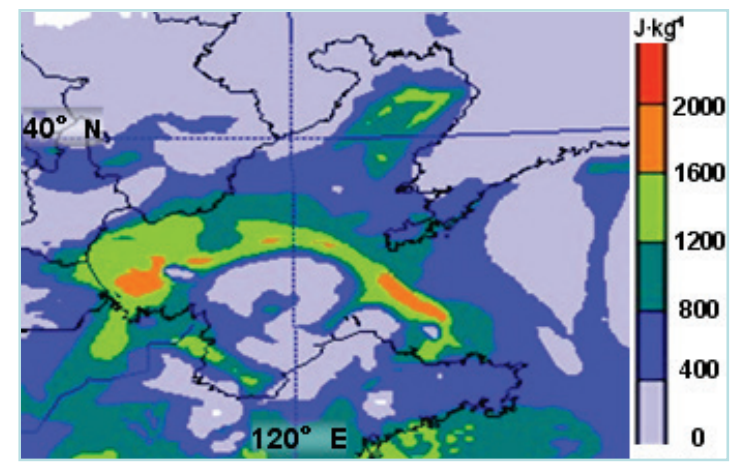

图 8.2015 年 8 月 31 日 14 时（CST）初始场 WRF 模式模拟渤海区域 9 月 1 日 01 时对流有 效位能 (CAPE) 


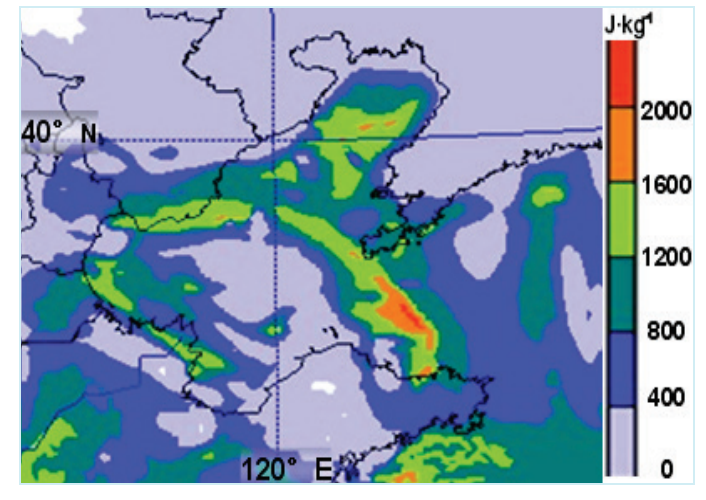

图 9.2015 年 8 月 31 日 20 时 (CST) 初始场 WRF 模式模拟渤海区域 9 月 1 日 01 时对流有 效位能 (CAPE)

\section{3 假相当位温}

另外一个值得关注的热力因子为假相当 位温, 是一种守恒的量, 可以利用它来分析大 气的热力性质。大尺度背景下, 假相当位温等 值线密集区附近有利于浴旋的发展, 把大值区 和能量场空间分布作为强降水发生的必要条 件。在中尺度系统分析中, 作为饱和气层静力 稳定度的基本判据。如（图 10） $\Delta \theta$ se 整个 空间 1000-300 hPa 垂直值域分布为低层大, 中间层小，高层大有利于对流天气发生发展， 从 20 时至 02 时中尺度低值气团 $\left(280^{\circ} \mathrm{K}\right)$ 前 沿由 $124^{\circ} \mathrm{E}$ 向西推进到 $123^{\circ} \mathrm{E}$ 附近, 高度下降, 在辽东湾东北 $\Delta \theta \mathrm{se}(925-700 \mathrm{hPa})$ 较弱干冷 切入, 相对于 $39^{\circ} \mathrm{N}$ 以南海区有利对流系统的 发生, 而相对 $39^{\circ} \mathrm{N}$ 以北区域及落区不利于发 生发展。

\section{4. 渤海旅游船舶强对流天气预警指标初 建}

\section{$4.1 E C 、 W R F$ 模式海区强对流产品应用技 术}

利用 EC 细网格、本地海洋气象与环境 WRF 模式应用技术, 典型个例综合分析, 采用备份 服务器回放技术, 1 小时 $\times 5$ 公里格点资料 (0-24 小时预报场) : (1)强对流天气物理量剖
面 $\left(39 \mathrm{~N}^{\mathrm{o}}, 116-126 \mathrm{E}^{\circ}\right)$ (2) $0-24$ 小时降水 +10 米风场(3)1000 百帕 +10 米相对湿度等并提供 最大海浪监测与预测信息, 建立 0-24 小时潜 势预报和 1-3 小时海区强对流预警指标。

\section{2 秦皇岛海区强对流预警模型}

1 小时预报预警：雷达反射率因子+雷电 监测 + 海岛站+浮标

2 小时预报预警：雷达反射率因子+雷达 拼图+海岛站+浮标+探空

3 小时预报预警：雷达反射率因子+卫星 云图 SWAP+WRF3 小时物理量

0-24 小时潜势预报： $\mathrm{EC}+\mathrm{WRF}$ 物理量 +WRFCAPE+中央台 SPC

\section{3 强对流发布方式及应用}

通过海事值班通讯 VTS 平台 (船舶交通管 理系统）及微信方式, 实时发布预警信息至船 长和值班经理。内容格式: 中国气象局预警信 号标准模板或图片格式。2016 年 7-8 月共发 布秦皇岛近海强对流天气预警 5 次，其中， 7 月 20 日、25 日在 AIS 系统下, 预报员用卫星 电话或手机直接与船长通话, 王子号、公主号 及长城号三艘游轮均提前 1 小时安全返航。

\section{5. 结论}

海洋强对流天气是目前渤海旅游船舶预 警技术难点之一。大多数渤海强对流天气系统 是大气西风带环流背景下, 由陆地西部或北部 生成后移向海区的, 直接由渤海南部区域生成 的强对流系统移向西北方向的个例甚少。分析 结论如下:

(1) 环渤海地区天气尺度系统的有效配 置为不同时段的中尺度对流系统发展提供了 环流背景条件。0 8 时 -20 时渤海湾一线 925-850 百帕切变线东移增强, 08 时临近探空 $\mathrm{K}$ 指数 $35^{\circ} \mathrm{C}$ 、 $\mathrm{SI}$ 指数 $-1.81^{\circ} \mathrm{C}$ 及 $\mathrm{CAPE}$ 为 $166 \mathrm{~J} / \mathrm{kg}$, 垂直风切变 $16 \mathrm{~m} \bullet \mathrm{S}^{-1}$, 导致天津一线 的强对流天气发生。20-02 时其前部低层 925 百帕 “暖式切变线” 北抬, 对流性不稳定能量
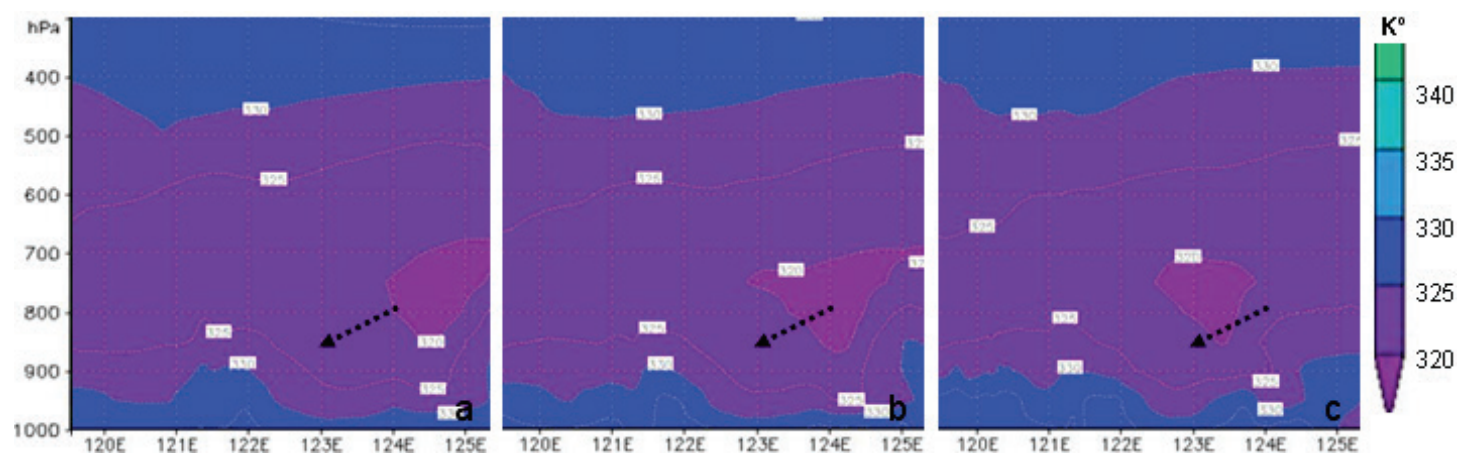

图 10.2015 年 8 月 31 日 14 时 (CST) 初始场 WRF 模式 $39^{\circ} \mathrm{N}$ 假相当位温剖面 a. 20 时 b. 23 时 c. 02 时 
增强, 在渤海中部的切变线附近诱发多个中 $\gamma 、 \beta$ 尺度强对流风暴单体，在雷达回波 “列 车效应” 下, 造成了秦皇岛近海新一轮强对流 天气过程。

（2）在渤海湾一带生成的多单体风暴稳 定少动, 15 时雷达反射率因子强回波带水平 尺度 $230 \times 80 \mathrm{~km}$, 强度 $40-50 \mathrm{dbz}$, 移向 $\mathrm{W} \rightarrow \mathrm{E}$ 向, 移速为 $20 \rightarrow 30 \mathrm{~km} / \mathrm{h}$, 对应天气短时强降 水、雷电等; 2 小时后东移莱州湾维持发展。 20 时渤海南部中尺度强对流回波带北抬发展, 强回波带水平尺度 $350 \times 80 \mathrm{~km}$, 强度 40-55dbz, 移向 SSW $\rightarrow \mathrm{NNE}$ 向, 移速为 $30 \rightarrow$ $40 \mathrm{~km} / \mathrm{h}$, 在渤海中部的切变线附近诱发多个中 $\gamma 、 \beta$ 尺度强对流风暴单体与主体回波带移向 成 $90^{\circ}$ 交角, 水平尺度 $30 \times 50 \mathrm{~km}$, 强度 $50-55 \mathrm{dbz}$, 移向 $\mathrm{SE} \rightarrow \mathrm{NW}$ 向, 移速为 $50 \rightarrow$ $60 \mathrm{~km} / \mathrm{h}$, 具有明显的向前传播线性特征, 即雷 达回波 “列车效应”。03 时 (CST) 中部海区 回波带出现断裂, 强度下降至 30-40dBz, 04 时趋于消亡。

（3）通过典型个例分析初步建立预警模 型。1-3 小时预报预警: 雷达反射率因子+雷 电监测+海岛站+浮标; $0-12$ 小时潜势预报: $\mathrm{EC}+\mathrm{WRF}$ 物理量+WRFCAPE+中央台 SPC。在 2016 年 7-8 月实际应用中取得令人满意的效果。

\section{致谢}

项目资助: 环渤海区域科技协同创新基金项目 (黄渤海雷暴大风监测及预警指标研究 QYXM201502)。

\section{参考文献}

[1]王彦. 风锋雷达回波特征分析 [J]. 气象, 2006，32(12):23-28.

[2] 贺靓, 于超, 吕新民. 渤海中南部海区一次 雷暴大风过程分析. 海洋预报, 2011, 28(1) : 19-24.

[3] 郭庆利, 薛袭波, 党英娜. 渤海海峡雷雨大 风的多普勒雷达回波特征. 海洋预报, 2011，28(1):13-18.

[4] 孙树琴. 一次由 “列车效应 “引发的梅雨 锋暴雨研究. 高原气象, 2015，34(1)：190201.

[5]S.J. Guo, The Meteorological Disaster Risk Assessment Based on the Diffusion Mechanism. Journal of Risk Analysis and Crisis Response, 2012, 2(2): 124-130.

[6]W. Wang, C. Zhou. The Research of a Hail Risk Evaluation under Imperfect Information Journal of Risk Analysis and Crisis Response, 2011, 1(2): 133-141. 